\title{
JOB BURNOUT AND ENGAGEMENT AMONG TEACHERS - WORKLIFE AREAS AND PERSONALITY TRAITS AS PREDICTORS OF RELATIONSHIPS WITH WORK
}

\author{
JUSTYNA MOJSA-KAJA, KRYSTYNA GOLONKA, and TADEUSZ MAREK
}

Jagiellonian University, Kraków, Poland

Institute of Applied Psychology, Department of Cognitive Neuroscience and Neuroergonomics

\begin{abstract}
Objectives: The main goal of the present study was to analyze the burnout syndrome due to selected personality traits (based on the Cloninger's psychobiological personality model and positive and negative affectivity) and the degree of mismatch between teachers and their work environment (described in terms of the Model of Worklife Areas). The 2nd goal was to determine if the participants could be classified into different burnout profile groups (clusters) based on their burnout dimension (exhaustion, cynicism and efficacy) scores and whether those groups differed significantly with regard to their personality traits and levels of mismatch between them and the workplace. Material and Methods: Individual and contextual factors responsible for burnout were analyzed in a group of 205 Polish teachers who completed a set of questionnaires: Maslach Burnout Inventory - General Scale, Areas of Worklife Scale, Temperament and Character Inventory, and Positive and Negative Affect Schedule. Results: The hierarchical regression analysis revealed that teachers' efficacy is determined only by personality factors, while exhaustion and cynicism are determined by both individual and organizational variables. The cluster analysis revealed 3 groups (burnout, engaged, ineffective) that varied in the level of all burnout dimensions. Teachers experiencing burnout perceived a higher level of mismatch between themselves and the work environment, compared to the engaged teachers demonstrating better alignment. The engaged teachers were lower on negative affectivity and higher on self-directedness as compared to the burnout group. Conclusions: The study provided insight into the role of individual factors in the development of teacher burnout and engagement. Negative affectivity could be considered as a predisposing risk factor and self-directedness as a protective factor for burnout.
\end{abstract}

Key words:

Burnout, Teachers, Engagement, Individual differences, Worklife areas

\section{INTRODUCTION}

Previously, burnout research was conducted in the context of the care-giving and service professions in which relationships between providers (doctors, nurses, psychotherapists and teachers) and recipients (patients and students) play a fundamental role [1]. Gradually with time, the concept of burnout has been extended to a wider context than human services and education, and has been described in terms of a crisis between an employee and their job, and not necessarily as a crisis in interpersonal relationships at work [2]. Consequently, the burnout syndrome has been characterized by the state of exhaustion

Received: March 5, 2014. Accepted: September 19, 2014.

Corresponding author: J. Mojsa-Kaja, Jagiellonian University, Institute of Applied Psychology, Department of Cognitive Neuroscience and Neuroergonomics, Lojasiewicza 4, 30-348 Kraków, Poland (e-mail: justyna.mojsa-kaja@uj.edu.pl). 
in which individuals become cynical in relation to their work and suffer from decreased professional efficacy [3].

\section{Engagement with work}

Burnout and work engagement are mostly described as the opposite ends of the continuum in the relationship people establish with their jobs. According to Maslach et al. [3], engagement is characterized by energy (rather than exhaustion), involvement (rather than cynicism) and higher professional efficacy ratings (rather than reduced professional efficacy).

In other models, however, engagement is not the polar opposite to burnout and is viewed as a relatively distinct concept. It was introduced by Schaufeli et al. [4] and Schaufeli and Bakker [5] and is described by 3 dimensions: vigor (high energy, willingness to invest effort), dedication (sense of involvement at work), and absorption (being concentrated on one's work). However, recent research provides some evidence for only one continuum [6]. The authors have concluded that for scientific and practical reasons it should be assumed that there was no need to distinguish 2 separate constructs. Therefore, in this article we concentrate on the burnout and engagement model of Leiter and Maslach [7] whilst taking into account that burnout and engagement are the opposite poles of the same continuum.

\section{Burnout and health}

Job burnout has implications for physical and psychological health. It has been confirmed that physical illness is more common among subjects with burnout and the prevalence of disease increases with the severity of this syndrome [8,9]. Schaufeli and Enzmann [10] emphasized the difference between psychosomatic complaints and the health problems linked with burnout. The former refer to subjectively measured complaints which are difficult to verify objectively (e.g., neurasthenic symptoms, fatigue, heart or circulatory disturbances and gastrointestinal complaints), whereas the latter are based on objective diagnoses (e.g., musculoskeletal disorders and cardiovascular diseases). Moreover, several studies have shown the connection between burnout and depression, which is the most extensively studied correlate of this stress-related syndrome [11,12].

Finally, studies presented by Bakker [13] suggest that burnout not only impacts employees' health, but also other people's health as it can transfer between partners, affecting their psychological health. Only a few studies report on the correlations between burnout and maladaptive coping mechanisms such as smoking, alcohol use, consumption of medicaments or drug use [e.g., 10,14]. The research provides mixed results and it seems that substance use is weakly, if at all, correlated with burnout.

\section{Antecedents of burnout}

Extensive research has identified a variety of factors determining burnout which have traditionally been divided into 2 separate groups: situational and individual antecedents [10]. The former refers to: job characteristics (e.g., quantitative job demands: overload, time pressure, qualitative job demands: role conflict and ambiguity, absence of job resources: lack of social support from supervisors and co-workers, control and autonomy); occupational characteristics (e.g., the requirement to display or suppress emotions at work) and organizational characteristics (e.g., conflict between organizational and employee's values). Individual antecedents include demographic variables (age, sex, marital status, level of education); workrelated attitudes (e.g., high and unrealistic expectations) and personality characteristics.

The vast majority of research has been devoted to the role of situational factors neglecting the importance of personality traits in the etiology of the syndrome [15]. Recently, it has been assumed that personality can play a role in the ways someone reacts to the environment [16]. Some people seem to be predisposed to react more strongly than others in a similar situation [17]. Overall, many studies 
support the notion that certain aspects of personality can affect average stress levels and stress-related disorders such as burnout [18]. Among individual characteristics, the most often considered were personality traits such as a high level of neuroticism, negative affectivity [19], temperamental traits responsible for low abilities of stimulation processing such as high perseverance and emotional reactivity, low tendency to sensation seeking $[18,20]$, low levels of hardiness, and other factors such as external locus of control, poor self-esteem, type A behavior, and avoidant coping style [3]. Therefore, these traits constitute the profile of a burnout-prone employee. On the other hand, Tucholska [21] described a protective personality profile of engaged individuals in terms of resilience, internal integration and good emotional control.

\section{Areas of Worklife Model}

Recently, research on burnout has begun to develop new theoretical frameworks that integrate both individual and situational factors, instead of considering them in separate ways. Maslach et al. [3] have begun to address this challenge by providing a model that focuses on the degree of match or mismatch between a person and the 6 domains of his or her work environment. Based on a literature review, the authors summarized a wide range of research on workplace factors related to burnout and provided the Six Areas of Worklife as predictors of burnout [7]. This model proposes 6 areas of worklife that cover the crucial relationships with burnout: workload, control, reward, community, fairness and values.

According to this model, burnout stems from chronic mismatches between people and their work setting in terms of some or all of these 6 areas. An employee's psychological relationship with his or her job has been conceptualized as a continuum between the negative experience of burnout and the positive experience of engagement [7,22]. The greater the mismatch between the person and the job, the greater the probability of burnout; conversely, the greater the match, the greater the likelihood of engagement at work [23]. To sum up, a model of 6 areas of worklife has been developed in which incongruities are predictive of burnout (risk factors), and conversely, congruities are predictive of engagement (protective factors).

\section{Sources and outcomes of teacher burnout}

Although the burnout syndrome can occur in any profession, it is most common in occupations with strong social interactions, especially among teachers whose profession is considered to be one of the most stressful [24-26]. Educators have the highest stress and burnout levels compared to workers in other human services and other jobs [27]. In comparison with other professional groups, teachers show higher levels of exhaustion and cynicism, the crucial dimensions of the burnout syndrome [3].

Frequently identified sources of stress among teachers include: inadequate salary and the perceived low status of the profession [28], role conflict and ambiguity [29], time pressure [30], student misbehavior, relationships with supervisors [31], emotional demands [32], working conditions, lack of resources and social support (for a relevant review see [33]). A study conducted on a large group of Polish teachers showed that the most significant sources of stress were: inadequate salary, extensive workload, lack of control, teacher-student ratio, lack of social support from supervisors and co-workers, student misbehavior and mobbing [34]. Personality traits have been demonstrated to increase vulnerability to stress-related psychopathology [35]. Regarding personality correlates of teacher burnout, Fontana and Abouserie [36], using the Eysenck model of personality, found associations between burnout and high scores in neuroticism, introversion and psychoticism. Mills and Huebner [37], using the Big-Five factor model of personality, demonstrated that neuroticism and introversion correlate with the 3 factors of burnout.

Similarly, Cano-Garcia and co-authors [33] found that the highest levels of burnout were observed in teachers 
scoring high in neuroticism and introversion. Moreover, emotional exhaustion was associated with levels of conscientiousness and agreeableness, depersonalization was associated with agreeableness, and personal accomplishment with conscientiousness [37]. Kokkinos [38] has found that neuroticism was a common predictor of all the dimensions of burnout, although it had the opposite relation with personal accomplishment. Conscientiousness appeared to be a key personality trait that was associated with depersonalization and personal accomplishment.

Finally, positive and negative affectivity, constituting the 2-dimensional model of personality, have been considered by some researchers as predictors of burnout and engagement $[18,39]$. The traits of positive and negative affectivity correspond to the dominant personality factors of extraversion and neuroticism, respectively [40]. Extraversion is comprised of self-confidence, dominance, activity and sensation-seeking. While individuals low in extraversion appear quiet or reserved, those high in extraversion are energetic and cheerful, possibly because they engage in more activities to overcome stressful conditions.

The study conducted by Iverson et al. [41] showed that workers who were higher in positive affectivity experienced less burnout. Neuroticism reflects feelings of distress and underlies the chronic emotional experience of guilt and frustration. Neurotic individuals are emotionally unstable and prone to psychological distress, so this personality correlate of burnout is theoretically explained and empirically verified [42].

The mental and physical health of many teachers has been adversely affected by burnout [43]. Positive correlations in a group of educators [14] have also been observed between emotional exhaustion, and frequency and intensity of somatic complaints. Moreover, negative health behaviors (e.g., excessive alcohol consumption) were associated with higher teacher burnout [44]. Finally, the data show that psychosomatic disorders and symptoms that correlate with burnout turned out to be the main cause of increasing rates of premature retirement among school teachers [45].

Despite the fact that the negative aspects of teaching dominate in occupational health literature, it is essential to emphasize that the vast majority of teachers are engaged and motivated and find their work rewarding and satisfying [46]. Therefore, it is essential to analyze both individual and organizational factors related to the job stress phenomenon known as burnout and its opposite, i.e., is work engagement.

\section{Aims of the study}

Although burnout can be explained as the transactional outcome of triggering contextual variables and the facilitating or inhibiting effect of personality variables [47], research has rarely considered the role of personality variables as determinants of burnout, especially in teachers [38]. Therefore, it remains an intriguing question why some employees report high levels of burnout, whereas others working in the same environment do not [15]. However, there is a growing body of research analyzing the role of personality traits in the occurrence of stressrelated consequences, most of them being based on the Big-Five factor model of personality. There is a notable lack of research expanding the links between burnout and other personality models defined in terms of psychobiological factors.

Moreover, so far, there has been no empirical study based on the Cloninger's psychobiological personality model $[48,49]$ and burnout among teachers. Finally, there is no study implementing the Areas of Worklife Model [7] in educational settings. Consequently, the aim of the present research was to investigate how individual differences, based on the psychobiological model of personality and positive and negative affectivity, are related to teacher burnout. Taking into consideration that burnout is a prolonged response to chronic emotional and interpersonal stressors on the job [3], and that Cloninger's personality 
dimensions influence individual's stress vulnerability [50], it is justified to assume that personality traits influence the relationships between stressors (understood as a mismatch between employees and their work setting) and stress consequences defined as burnout. Generally, the main goal of the present study was to analyze the model of burnout focusing on the integration of employee's personality traits and the degree of mismatch between them and their work environment (described in terms of 6 worklife areas).

Therefore, we attempted to answer the following research questions:

1. What personality traits are associated with each of the burnout dimensions?

2. What are the relationships between burnout dimensions and incongruities in the areas of worklife?

3. Are there any homogeneous subgroups of teachers classified on the basis of levels of burnout dimensions?

4. What are the differences in personality profiles between homogeneous subgroups?

5. What are the differences in congruence between worklife domains and teachers from different subgroups?

\section{MATERIAL AND METHODS}

\section{Participants and procedure}

The present study was carried out in Poland (2006-2007). Firstly, the authors provided paper questionnaire packages to 10 schools randomly selected from a list of secondary schools located in the Małopolska Province. Participation in the study involved completion of the questionnaire package and the participants volunteered without any financial compensation. School headmasters were responsible for distributing the packages to secondary school teachers.

There were 450 questionnaire packages distributed, accompanied by a letter detailing the procedure and reason for the study as well as emphasizing the confidentiality and anonymity of the responses. A total of 300 packages were returned, including 205 completed questionnaires. The final sample contained teachers who had obtained an academic master's degree, with $69.8 \%$ of female $(\mathrm{N}=143)$ and $30.2 \%$ of male $(\mathrm{N}=62)$ participants. Their age varied between 24-61 years $($ mean $(\mathrm{M})=40.5$, standard deviation $(\mathrm{SD})=9.5$ ) and on average they had worked as teachers for 14.4 years $(\mathrm{SD}=8.8)$.

\section{Measures}

Burnout was measured using the Maslach Burnout Inventory - General Scale (MBI-GS [2]; the Polish version provided by Mojsa et al. [51]). The MBI-GS measures the 3 dimensions of burnout and consists of 16 items that are rated on a 7-point frequency scale (ranging from 0 never to 6 - every day). The items measuring exhaustion (5 items) refer to both physical and emotional exhaustion. The cynicism dimension (5 items) reflects detachment and distance from the job itself. Finally, professional efficacy (6 items) relates to both social and non-social aspects of occupational accomplishments and refers to the individual's expectations of continued effectiveness at work. Burnout is reflected in higher scores on exhaustion and cynicism and lower scores on efficacy, while the opposite pattern reflects greater engagement. The MBI-GS had been previously successfully used in research on burnout among teachers [52]. Previous studies concerning psychometric evaluation of the Polish version of the MBI-GS evaluating its reliability and factorial validity $[51,53]$ had proven satisfactory psychometric equivalence with the original method.

Areas of worklife were measured using the Areas of Worklife Scale (AWS) [54] that is composed of 29 items which create distinct scores for each of the 6 areas of worklife (workload, control, reward, community, fairness and values).

Workload refers to the relationship of work demands with time and resources. Control refers to role clarity within the organization that provides a clear understanding of expectations and responsibilities. Reward refers 
to recognition from other people as well as satisfaction that employees experience in the workplace. Community includes the quality of social relationships within the organization. Fairness in the workplace involves perception of organizational justice. Finally, values refer to the congruence between the employee's values, goals and expectations and those of the organization.

The items are framed as statements of perceived congruence or incongruence between oneself and the job. Each subscale includes positively worded items of congruence e.g., "I have enough time to do what's important in my job" (manageable workload) and negatively worded items of incongruence, e.g., "Working here forces me to compromise my values" (values). The items measuring workload (6), control (3), reward (4), community (5), fairness (6), and values (5) are rated on a 5-point Likert-type scale ranging from 1 - strongly disagree to 5 - strongly agree. The scoring for the negatively worded items is reversed.

For each of the 6 subscales, the AWS measure defines congruence as a high score $(>3)$, indicating a higher degree of perceived alignment between the workplace and the respondent's preferences. Conversely, it defines incongruence as a low score $(<3)$, indicating misfit between the employee and the workplace. Therefore, the AWS scores create a continuum from mismatch to match between the person and the job. The scale has yielded a consistent factor structure across samples [16]. The Polish version of the AWS showed good psychometric properties, including its internal consistency (all Cronbach's $\alpha$ coefficients were equal or $>0.70)$ [55].

Personality traits were assessed by the Temperament and Character Inventory (TCI [56]; the Polish version provided by Hornowska [57]). The measurement is based on the psychobiological theory of personality $[48,49]$ which measures 4 temperament dimensions (novelty seeking, harm avoidance, reward dependence and persistence) that are defined as genetically homogeneous and independently inherited.
Novelty Seeking (40 items) is a tendency towards exploratory activity in response to novelty, impulsive decision making, and extravagance in approach to cues of rewards and active avoidance of frustration. Harm Avoidance (35 items) is a tendency towards inhibition of behavior such as pessimistic worry in anticipation of future problems, passive avoidant behaviors such as fear of uncertainty and rapid fatigue, while Reward Dependence (24 items) is a tendency manifested in sentimentality, dependence on the approval of others and social attachment. Finally, Persistence ( 8 items) is a tendency to persevere despite frustration and fatigue.

Furthermore, the instrument measures 3 character dimensions (self-directedness, cooperativeness and selftranscendence) developed over a lifetime that reflect the differences between individuals' self-concepts, according to the extent of identification with themselves as autonomous individuals. Self-directedness (44 items) measures individual self-acceptance and responsibility for one's choices, Cooperativeness (42 items) measures acceptance of other people, empathy, compassion and helpfulness, while self-transcendence (33 items) captures the degree to which an individual feels as a part of nature and the universe at large. The questionnaire consists of 240 items worded as statements that are rated on a "true or false" scale. The reliability of each main scale of the Polish version of TCI was previously confirmed and it can be used for the assessment of personality dimensions both in experimental and clinical studies [58].

The Polish version of 20-item Positive and Negative Affect Schedule (PANAS [40]; Polish version provided by Brzozowski [59]) was used to measure the participants' positive affectivity (PA) and negative affectivity (NA). There are 10 emotions for each subscale (e.g., interested and excited for PA, distressed and upset for NA), and the participants rated the extent to which each emotion is generally experienced on a 5-point scale ranging from 1 - very 
slight or not at all to 5 - extreme. Higher scores reflect greater levels of PA and NA. These 2 factors correspond to affective trait dimensions of positive and negative emotionality (individual differences in positive and negative emotional reactivity). The PA and NA traits correspond to the dominant personality factors of extraversion and neuroticism, respectively [40]. The Polish version of PANAS had satisfactory psychometric equivalence with the original method [59].

\section{Statistical procedures}

The data were analyzed using Statistica 10 (StatSoft). The goal of hierarchical regression analyses was to examine to what extent the variables (personality traits and degree of fit between the participants and 6 worklife areas) would explain the 3 dimensions of burnout. Due to the fact that some demographic variables have been linked to burnout [60,61], the variables of gender and age were controlled for statistically. With each burnout dimension as the dependent variable, these control variables were 1st added to the regression equation (step 1), followed by the independent variables, i.e., dimensions of TCI, PANAS and AWS (step 2).

The secondary aim was to investigate what kind of a homogeneous group of employees could be identified in the sample according to their exhaustion, cynicism and efficacy. The k-means clustering procedure was employed to determine whether the participants could be classified into burnout profile groups based on their burnout dimension scores. Results for 2-, 3- and 4-cluster solutions were examined. While interpreting the results of the k-means clustering procedure, the mean values of each burnout dimension in each cluster were analyzed in order to estimate whether the clusters were different from each other. The F statistic from ANOVA served as an indicator of differences between clusters with regard to burnout dimensions. Finally, ANOVA and Tuckey's post hoc tests were used to determine whether people in these 3 clusters differed significantly in terms of personality variables and the degree of perceived alignment between them and their worklife areas.

\section{RESULTS}

\section{Descriptive statistics, correlations and reliability}

Table 1 presents the correlations among the measures, means, standard deviations and Cronbach's $\alpha$ values. All the variables demonstrated acceptable reliability, above 0.70 , with the exception of persistence (Cronbach's $\alpha=0.59$ ), this probably being due to there being fewer items in this scale compared to the number of items in other TCI scales. It is worth noting that there is a debate over the persistence trait as a reliable dimension of temperament [62].

\section{Regression analyses}

The results of the hierarchical regression analyses are presented in Table 2. A regression analysis has shown that both individual and organizational variables were predictors of exhaustion and cynicism. Concerning exhaustion, the strongest predictor was incongruence between teachers and their job in the area of perceived workload and also individual factors such as negative affectivity, selfdirectedness, persistence and novelty seeking. Finally, the organizational factor predicting exhaustion was a perceived misalignment between teachers' expectations of control and the level of control present in the workplace. In the case of cynicism, the strongest predictors were personality traits such as novelty seeking, persistence and negative affectivity, while the weakest predictor was the organizational factor reflecting incongruence between teachers' perception of organizational justice and their expectations of fairness in the workplace. Finally, efficacy was determined only by individual variables. A negative predictor for this burnout dimension was negative affectivity, while positive predictors were positive affectivity and self-transcendence. 


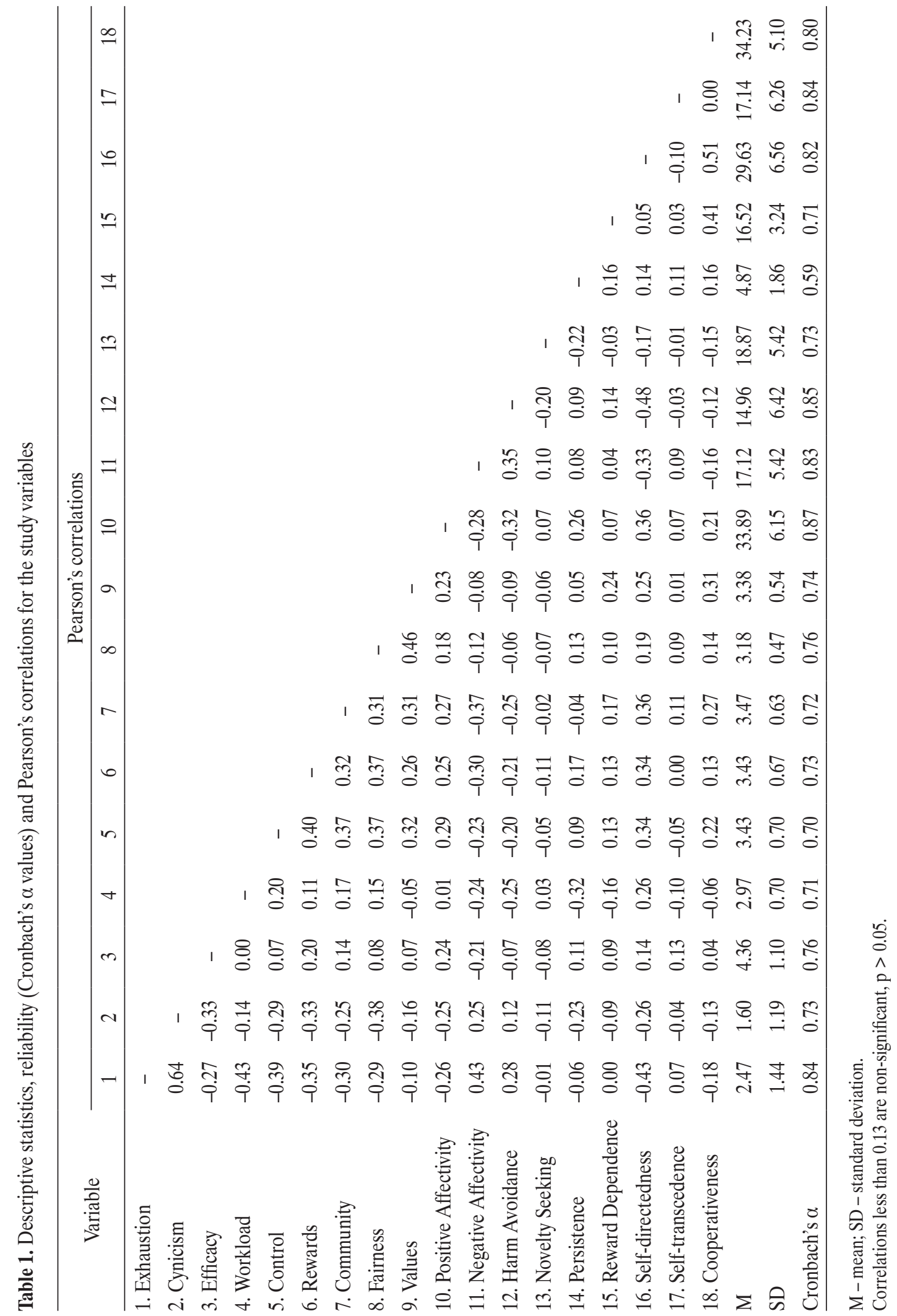


Table 2. Results of regression analyses for the predicting variables on exhaustion, cynicism and efficacy

\begin{tabular}{|c|c|c|}
\hline $\begin{array}{l}\text { Predicting } \\
\text { variable }\end{array}$ & $\beta$ & $\mathrm{R}^{2}$ \\
\hline \multicolumn{3}{|l|}{ Exhaustion } \\
\hline step 1 & & 0.03 \\
\hline gender & 0.02 & \\
\hline age & -0.03 & \\
\hline step 2 & & $0.46^{* * *}$ \\
\hline workload & $-0.30^{* * *}$ & \\
\hline negative affectivity & $0.26^{* * *}$ & \\
\hline self-directedness & $-0.17^{*}$ & \\
\hline persistence & $-0.15^{*}$ & \\
\hline novelty seeking & $-0.14^{*}$ & \\
\hline control & $-0.14^{*}$ & \\
\hline \multicolumn{3}{|l|}{ Cynicism } \\
\hline step 1 & & 0.01 \\
\hline gender & 0.04 & \\
\hline age & -0.06 & \\
\hline step 2 & & $0.30 * * *$ \\
\hline novelty seeking & $-0.26^{* * *}$ & \\
\hline persistence & $-0.25^{* * *}$ & \\
\hline negative affectivity & $0.18^{* *}$ & \\
\hline fairness & $-0.16^{*}$ & \\
\hline \multicolumn{3}{|l|}{ Efficacy } \\
\hline step 1 & & 0.01 \\
\hline gender & -0.03 & \\
\hline age & 0.07 & \\
\hline step 2 & & $0.16^{*}$ \\
\hline negative affectivity & $-0.20^{*}$ & \\
\hline positive affectivity & $0.17^{*}$ & \\
\hline self-transcendence & $0.16^{*}$ & \\
\hline
\end{tabular}

$\beta$ - standardized regression coefficient; $\mathrm{R}^{2}$ - coefficient of determination. ${ }^{*} \mathrm{p}<0.05 ;{ }^{* *} \mathrm{p}<0.01 ;{ }^{* * *} \mathrm{p}<0.001$.

\section{Cluster analyses}

Based on empirical findings, the 3-cluster solution (Figure 1) was determined to be the best fit as it provided conceptually interesting contrast groups and contained

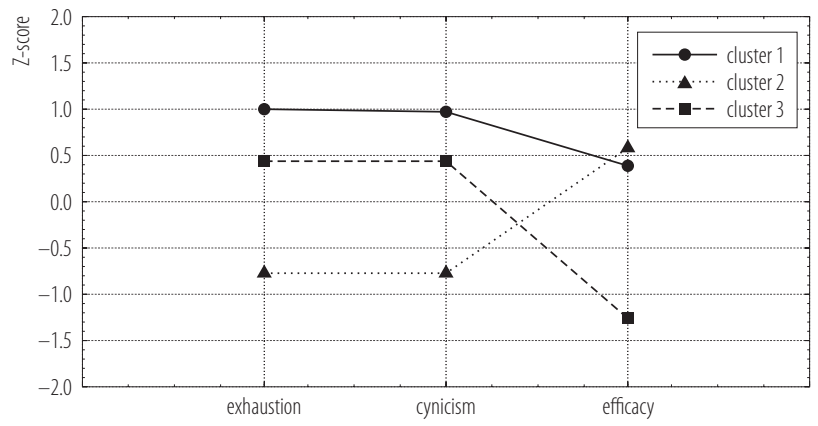

Fig. 1. Three clusters (burnout profile groups) based on their burnout dimension scores

adequate participants in each cluster to allow for further empirical testing. The unstandardized means, standard deviations, z scores, ANOVA results and Tuckey's post hoc tests for each burnout scale across the 3 clusters are presented in Table 3.

A z score of \pm 0.5 was used as a criterion to interpret profile groups as low, moderate or high on the 3 burnout dimensions. A z score below -0.5 was classified as low, a $z$ score above -0.5 and below +0.5 was classified as moderate, and a $z$ score above +0.5 was classified as high. Cluster 1 comprised 50 teachers $(24.4 \%$ of all the participants) who were high in exhaustion and cynicism and moderate in efficacy. Of the 3 MBI-GS dimensions, exhaustion and cynicism are 2 basic measures of burnout that simultaneously appear in people experiencing burnout and are not reported among people experiencing engagement with their work [23]. Therefore, it was assumed that Cluster 1 should be labeled as "Burnout". Cluster 2 was composed of 96 participants $(46.8 \%$ of all the participants) who were low in exhaustion and cynicism and high in efficacy. Therefore, they present pattern characteristics for engagement, which is the opposite of burnout syndrome, this being the reason that Cluster 2 was labeled "Engagement". Finally, Cluster 3 was comprised of 59 teachers (28.8\% of all the participants) who were moderate in exhaustion and cynicism and low in efficacy. This cluster was named "Inefficacy". 
Table 3. Descriptive statistics for burnout - engagement profile groups

\begin{tabular}{|c|c|c|c|c|c|c|c|c|c|c|c|c|}
\hline \multirow[t]{2}{*}{$\begin{array}{c}\text { Burnout } \\
\text { dimensions } \\
\text { (MBI-GS) }\end{array}$} & \multicolumn{3}{|c|}{$\begin{array}{c}1 \\
\text { "Burnout" } \\
(\mathrm{N}=50)\end{array}$} & \multicolumn{3}{|c|}{$\begin{array}{c}2 \\
\text { "Engagement" } \\
(\mathrm{N}=96)\end{array}$} & \multicolumn{3}{|c|}{$\begin{array}{c}3 \\
\text { "Inefficacy" } \\
(\mathrm{N}=59) \\
\end{array}$} & \multicolumn{2}{|c|}{ ANOVA } & \multirow[t]{2}{*}{$\begin{array}{l}\text { Post hoc } \\
\text { tests } \\
\alpha=0.001\end{array}$} \\
\hline & $\mathrm{z}$ & $\mathrm{M}$ & SD & $\mathrm{Z}$ & $\mathrm{M}$ & SD & $\mathrm{z}$ & $\mathrm{M}$ & $\mathrm{SD}$ & $\mathrm{F}$ & $\mathrm{p}$ & \\
\hline xhau & 1.00 & 3.92 & 0.99 & -0.78 & 1.35 & 0.86 & 0.42 & 3.08 & 0.98 & 145.00 & 0.0001 & [1-2-3] \\
\hline ynicism & 0.97 & 2.76 & 1.12 & -0.76 & 0.70 & 0.61 & 0.41 & 2.09 & 0.77 & 122.32 & 0.0001 & [1-2-3] \\
\hline Efficacy & 0.39 & 4.79 & 0.63 & 0.58 & 5.00 & 0.62 & -1.28 & 2.95 & 0.67 & 204.86 & 0.0001 & [1-2-3] \\
\hline
\end{tabular}

MBI-GS - Maslach Burnout Inventory - General Scale.

1 - Cluster 1;2 - Cluster 2; 3 - Cluster 3.

$\mathrm{z}-\mathrm{z}$-score $=$ standardized score $; \mathrm{F}-\mathrm{F}$ statistic.

Other abbreviations as in Table 1.

\section{ANOVA and post hoc comparisons}

The results of ANOVA and Tuckey's post hoc tests for AWS, PANAS and TCI scales across the 3 clusters are displayed in Table 4.
Cluster 1 was composed of the participants experiencing burnout who perceived a higher level of mismatch between themselves and the job in the area of manageable workload (compared to the participants forming Cluster 2

Table 4. Comparisons of degree of perceived alignment between the participants and worklife areas, and personality traits across burnout - engagement profile groups

\begin{tabular}{|c|c|c|c|c|c|c|c|c|c|}
\hline \multirow[t]{2}{*}{ Worklife area } & \multicolumn{2}{|c|}{$\begin{array}{c}1 \\
\text { "Burnout" } \\
(\mathrm{N}=50)\end{array}$} & \multicolumn{2}{|c|}{$\begin{array}{c}2 \\
\text { "Engagement" } \\
(\mathrm{N}=96)\end{array}$} & \multicolumn{2}{|c|}{$\begin{array}{c}3 \\
\text { "Inefficacy" } \\
(\mathrm{N}=59) \\
\end{array}$} & \multicolumn{2}{|c|}{ ANOVA } & \multirow{2}{*}{$\begin{array}{c}\text { Post hoc } \\
\text { tests } \\
\alpha=0.001\end{array}$} \\
\hline & $\mathrm{M}$ & SD & $\mathrm{M}$ & SD & $\mathrm{M}$ & $\mathrm{SD}$ & $\mathrm{F}$ & $\mathrm{p}$ & \\
\hline Workload & 2.61 & 0.80 & 3.13 & 0.63 & 3.01 & 0.61 & 9.89 & 0.0001 & {$[1-2,3]$} \\
\hline Control & 3.18 & 0.78 & 3.59 & 0.63 & 3.38 & 0.67 & 6.34 & 0.0023 & {$[1-2]$} \\
\hline Rewards & 3.25 & 0.67 & 3.64 & 0.64 & 3.25 & 0.64 & 9.32 & 0.0001 & {$[2-1,3]$} \\
\hline Community & 3.27 & 0.67 & 3.62 & 0.60 & 3.39 & 0.59 & 6.26 & 0.0023 & {$[1-2]$} \\
\hline Fairness & 3.02 & 0.50 & 3.30 & 0.44 & 3.13 & 0.44 & 6.64 & 0.0016 & {$[1-2]$} \\
\hline Values & 3.32 & 0.45 & 3.42 & 0.57 & 3.34 & 0.58 & 0.66 & 0.5201 & - \\
\hline Positive Affectivity & 33.20 & 5.54 & 35.60 & 5.52 & 31.70 & 6.86 & 8.31 & 0.0003 & {$[2-3]$} \\
\hline Negative Affectivity & 19.18 & 5.46 & 15.30 & 4.21 & 18.32 & 6.20 & 11.56 & 0.0000 & {$[2-1,3]$} \\
\hline Harm Avoidance & 16.58 & 6.58 & 14.24 & 6.02 & 14.78 & 7.78 & 2.24 & 0.10870 & - \\
\hline Novelty Seeking & 17.74 & 5.35 & 18.80 & 4.95 & 19.93 & 6.06 & 2.26 & 0.10741 & - \\
\hline Persistence & 4.64 & 1.91 & 5.16 & 1.78 & 4.59 & 1.90 & 2.19 & 0.11429 & - \\
\hline Reward Dependence & 16.62 & 3.31 & 16.68 & 2.89 & 16.19 & 3.73 & 0.45 & 0.64077 & - \\
\hline Self-directedness & 27.34 & 5.74 & 31.68 & 5.96 & 28.25 & 7.20 & 9.81 & 0.00009 & {$[2-1,3]$} \\
\hline Self-transcedence & 17.44 & 6.24 & 17.54 & 6.52 & 16.24 & 5.82 & 0.87 & 0.42129 & - \\
\hline Cooperativeness & 33.28 & 4.97 & 34.95 & 4.77 & 33.83 & 5.63 & 2.02 & 0.13582 & - \\
\hline
\end{tabular}

Abbreviations as in Table 1 and 3. 
and 3) and a lower level of congruence with work in the aspects of control, community and fairness, compared to the Cluster 2 group. Therefore, there was a significant distinction between the "Burnout" and "Engagement" clusters in terms of the perceived degree of congruence between the employee and the work environment. Additionally, the participants in Cluster 2 "Engagement" showed a higher degree of perceived fit between the work environment and their preferences in the area of rewards, compared to the "Burnout" and "Inefficacy" clusters.

In terms of individual differences, Cluster 2 was comprised of the participants who experienced work engagement and showed significantly higher scores on positive affectivity, compared to Cluster 3 (ineffective teachers) and a higher level of self-directness compared to Cluster 1 and Cluster 3. Moreover, the participants in Cluster 2 were characterized by a lower level of negative affectivity compared to the 2 other clusters.

Finally, the teachers from Cluster 1 and Cluster 3 differed neither in personality profile nor degree of alignment between the worklife domains and their expectations (excluding workload).

\section{DISCUSSION AND CONCLUSIONS}

In the literature on burnout there is still a discussion concerning which category of variables (individual or contextual) is a stronger predictor of this syndrome. Some authors have found that contextual variables have more predictive value than those of personality [15]. However, other research on personality $[36,37]$ has shown that personality variables indicate a higher percentage of variance than contextual aspects.

The results of the presented study show that the efficacy of teachers is determined by personality factors, while exhaustion and cynicism are shown to be determined by both organizational and individual variables.

In terms of the degree of match between a person and the 6 domains of work environment, exhaustion, reflecting the stress dimension of burnout, is shown to be determined by a misfit between the teachers' expectations and the perceived workplace situation in the areas of workload and control, while cynicism is determined by misalignment between the teachers' expectations of fairness and perceived fairness. The presented results are consistent with other research outcomes [7,63] and correspond to earlier theories on job stress such as the demand-control model of Karasek and Theorell [64]. Further support is provided by the effort-reward imbalance model [65], which is focused on a lack of perceived fairness that might lead to job strain, and in consequence may result in professional burnout. This statement was empirically tested by Bakker et al. [66], who has proved that employees who experienced an effortreward imbalance reported higher levels on 2 of the 3 core dimensions of burnout (i.e., exhaustion and depersonalization) than those who did not experience such an imbalance. Higher negative affectivity and lower novelty seeking and persistence constitute a personality profile that may contribute to the development of exhaustion and cynicism. Additionally, lower self-directedness was linked with exhaustion. Therefore, these 2 primary burnout dimensions are determined by a similar personality profile. According to Cloninger [48], persons with a low degree of selfdirectedness are irresponsible, unreliable and have low social integration. Moreover, a lower level of persistence manifests as low perseverance, although fatigue or frustration may be a strong factor influencing the ability to deal with workload. Finally, higher negative affectivity increases a person's difficulty in coping with stressful events and probability of burnout development.

Lower negative affectivity and higher positive affectivity and self-transcendence are associated with efficacy. This suggests a slightly different personality profile for this burnout dimension. Self-transcendent individuals are spiritual, unpretentious, humble and fulfilled [49]. These traits are adaptively advantageous when people are confronted with life difficulties. Additionally, high energy and 
engagement, optimism, and social interest characteristics of these individuals suggest that they are more likely to be engaged and satisfied with their work in an educational setting.

The results are in line with previous research, concluding that efficacy is a more independent construct than other burnout dimensions. It shows a relatively low correlation with exhaustion and cynicism and a different pattern of correlations with other variables [23,67]. Moreover, there are some arguments stating that professional efficacy may be a separate factor of burnout and is probably more related to engagement [4]. The results show that burnout seems to be primarily related to neuroticism, while all 3 burnout dimensions are determined by negative affectivity, which is consistent with the earlier research $[37,38,68]$. However, although this is the 1st study on burnout among teachers which uses TCI to measure personality, these results are congruent with the previous research analyzing the relationships between personality traits and burnout employing measures of TCI and MBI in health care professions and physicians [69,70]. Further analyses were focused on investigating whether the participants could be classified into burnout profile groups based on their exhaustion, cynicism and efficacy level and determining whether the teachers in these clusters differed significantly with regard to personality traits and to the degree of perceived alignment between them and worklife areas. Based on empirical findings, 3 clusters were identified (Figure 2). The results of the presented study also show that there are more engaged than burned-out teachers, which is in line with earlier

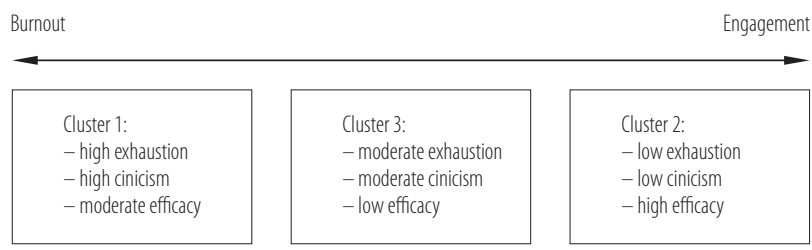

Fig. 2. Three clusters on the burnout - engagement continuum findings [52] and is an argument for further analysis of factors determining work engagement.

The current study shows that burned-out and engaged teachers can be distinguished on the basis of the degree of alignment between worklife areas and their preferences, as well as their personality profile. It appears that the participants experiencing burnout perceive a higher level of mismatch between themselves and the workplace in the areas of workload, control, rewards, community and fairness, compared to the engaged participants in Cluster 2. These results are congruent with the job demand-resource (JD-R) model often used to explain the burnout process [71]. According to this model, job demands (such as extensive workload and low control in our research) lead to employee's burnout due to physical or psychological effort, while job resources (such as rewards, community and fairness in our study) help decrease the feeling of burnout and are positive predictors of work engagement [72]. Therefore, the degree of perceived alignment between teacher's preferences and worklife domains, except for the area of values held by teachers, differentiated the burnout-engagement groups of the secondary school teachers. It is known from the literature that incongruence between the values held by employees and those held in an organization is an important variable determining the level of burnout and cannot be ignored. Leiter et al. [73] proved that value congruence was significantly related to all aspects of burnout and was described as playing a crucial role in the burnout model. It is interesting that although values play a crucial role in the Area of Worklife Model, they do not significantly vary between the 3 analyzed clusters. It may stem from the group homogeneity in terms of values in educational settings [74] and the fact that the work context did not differentiate the participants' values. The first 2 of the 3 analyzed clusters corresponded directly to the opposite poles of the burnout-engagement continuum [23]. The 3rd cluster displayed distinct characteristics, being featured by moderate exhaustion and cynicism, 
and in comparison to the other clusters, very low efficacy. This suggests that apart from burned-out and engaged employees, we might have also isolated and characterized a group of workers who, despite moderate levels of negative aspects of burnout, revealed very low efficacy, distinctly lower than in the burnout group. This group might be located between 2 opposite poles of 1 continuum: burnout and engagement. Taking into account the processual character of burnout, it may be hypothesized that the lower efficacy in this group is the 1st syndrome of an employee's decreasing engagement. If this process develops further, it may lead to higher cynicism and exhaustion (typical in the burnout group), while efficacy improves as an adaptation process to work demands.

When we focus on the personality traits of negative affectivity and self-directedness that differentiate this group, we find that this group was similar to the burnout profile (higher level of negative affectivity and lower level of selfdirectedness), while also demonstrating significantly lower positive affectivity compared to the engagement profile.

Similarly to the burned-out teachers with regard to organizational factors, the described group was characterized by a degree of perceived fit between teachers' expectations and perceived situations in the workplace, with the only significant difference being misalignment between the preferred and perceived workload. It was consistently confirmed that mismatches on workload aggravate exhaustion and that increased workload has a consistent relationship with burnout [7,22,23]. Therefore, extensive workload might be the most sensitive factor that allows for discriminating burnout from inefficacy.

There is not enough evidence yet to draw a clear conclusion from the presented research, but these findings may be an interesting point for further research in the area of the processual nature of burnout syndrome.

We could also assume that individual differences do matter when it comes to discriminating groups of employees who score high as regards burnout and work engagement.
Teachers in the engagement profile were lower in negative affectivity and higher in self-directedness compared to the 2 remaining groups. Thus, negative affectivity could be considered as a predisposing risk factor and self-directedness as a protective factor for burnout. Such individual differences may explain why some teachers develop stressrelated phenomena such as burnout, whereas others do not. Taken together, it seems that burnout and inefficacy are opposites of engagement only as far as negative affectivity and self-directedness levels are concerned. The expected reverse pattern [42] was not observed for positive affectivity, which only played a role in discriminating employees that experience work engagement and low efficacy. Finally, although temperament is considered to be responsible for the way in which employees react to stressful situations at work and how they cope with their consequences [75], in this research temperament, measured by TCI, did not play a role in discriminating the burned-out from professionally engaged teachers. The explanation for these results may come from a study provided by Cloninger [76], who found that character traits as measured by the TCI have been found to be strongly related to wellbeing, whereas temperament traits are only weakly associated with individual differences in well-being. The association of "wellness" with character strengths seems to be stronger and more consistent than with temperament [77]. Nowadays, in the trend of positive psychology [78,79], research has focused more on the positive aspects of individual functioning. From this point of view, when considering the presented results it may be concluded that positive affectivity and self-directedness play a crucial role in employee engagement. These findings are congruent with a study conducted by Cloninger and Zohar [77], which examined the relationships between character dimensions and aspects of health and happiness. The authors found that self-directedness was strongly associated with happiness, satisfaction with life, general health and perceived social support. Additionally, there is some evidence that 
self-directedness may be improved by counseling [80] and has an important mediating role in the relationship between persistence and positive affect [81]. Finally, Cloninger [82] stated that it was possible to improve character traits (such as self-directedness), and recent work on well-being has shown that the most effective methods of intervention/therapy focus on the development of positive emotions and character traits that underline well-being.

Therefore, our research expands the existing knowledge on this character dimension in the context of "psychological well-being" in the work environment and provides an empirical base for developing psychological training among teachers which focuses on reducing burnout and increasing engagement through strengthening of protective personality factors. Such individual-based interventions, mainly based on a cognitive-behavioral approach, have been previously described (for an overview of such programs see [10,83]).

Additionally, since high job demands (workload) differentiated burnout from engagement and inefficacy in the presented study, reducing extensive workload might be essential from the preventive point of view. Many organization-based strategies exist to tackle high job demands, such as job redesign and more flexible work schedules (for an overview see [84]). On the other hand, designing programs focused on expanding job resources (such as rewards, community and fairness) may help decrease the feeling of burnout and increase work engagement among educators.

Finally, the recognition of the 6 areas of person-job mismatch expands the spectrum of options for intervention. Teachers may be able to tolerate greater workload if they feel well-rewarded for their efforts and if they value their work with children. Therefore, an intervention could target not only the area of workload, but also value and reward [7]. We hope that the current results contribute to a better understanding of teachers' well-being and factors related to burnout reduction and engagement increase and may find practical implications in both individual and organizational interventions in educational settings.

\section{Limitations}

The current study has some limitations that should be noted. Firstly, the presented study had a cross-sectional character, therefore, it was not possible to analyze the causal relationships between the variables. A longitudinal study is required to examine the casual relationships in levels of mismatch between teachers and their workplace, and burnout/engagement.

Secondly, all the data were based on self-reports. In the future, research on additional and more objective methods of mismatch between an employee and work environment (e.g., principal's assessment) should be implemented. Finally, the presented research included a sample of Polish teachers only, therefore, the socio-cultural context may also be a significant factor. The specifics of the educational systems in different countries, broadly defined working conditions and rewards, as well as the dominant values of employees, which Hofstede and Hofstede [85] refer to as a wider national context, should be taken into consideration. This may limit the possibility of generalization of the research results. Analysis of the broader cultural context is a very complex issue and it is not the aim of the presented article. However, further cross-cultural comparative studies on burnout should certainly be taken into account.

\section{REFERENCES}

1. Maslach C, Schaufeli WB. Historical and conceptual development of burnout. In: Schaufeli WB, Maslach C, Marek T, editors. Professional burnout: Recent developments in theory and research. Washington DC: Taylor \& Francis; 1993. p. 1-16.

2. Maslach C, Jackson SE, Leiter ME. The Maslach burnout inventory - General survey manual. 3rd ed. Palo Alto: Consulting Psychologist Press; 1996. 
3. Maslach C, Schaufeli WB, Leiter MP. Job burnout. Ann Rev Psychol. 2001;52(1):397-422, http://dx.doi.org/10.1146/ annurev.psych.52.1.397.

4. Schaufeli WB, Salanova M, Gonzales-Roma V, Bakker A. The measurement of engagement and burnout: A 2 sample confirmatory factor analytic approach. J Happ Stud. 2002; 3(1):71-92, http://dx.doi.org/10.1023/A:1015630930326.

5. Schaufeli WB, Bakker AB. UWES - Utrecht Work Engagement Scale: Test manual. Utrecht: Utrecht University, Occupational Health Psychology Unit; 2003.

6. Cole MS, Walter F, Bedeian AG, O'Boyle EH. Job burnout and employee engagement: A meta-analytic examination of construct proliferation. J Manage. 2012;38(5):1550-81, http://dx.doi.org/10.1177/0149206311415252.

7. Leiter MP, Maslach C. Areas of worklife: A structured approach to organizational predictors of job burnout. In: Perrewe P, Ganster DC, editors. Research in occupational stress and well being. Emotional and physiological processes and positive intervention strategies. Oxford: Elsevier; 2004. p. 91-134.

8. Ahola K. Occupational burnout and health. Helsinki: Finnish Institute Occupational Health; 2007.

9. Honkonen T, Ahola K, Pertovaara M, Isometsä E, Kalimo R, Nykyri E, et al. The association between burnout and physical illness in the general population - Results from the Finnish Health 2000 Study. J Psychosom Res. 2006;61(1):59-66, http://dx.doi.org/10.1016/j.jpsychores.2005.10.002.

10. Schaufeli WB, Enzmann D. The burnout companion to study and practice: A critical analysis. London: Taylor \& Francis; 1998.

11. Bakker AB, Schaufeli WB, Demerouti E, Janssen PP, van der Hulst R, Brouwer J. Using equity theory to examine the difference between burnout and depression. Anxiety Stress Coping. 2000;13(3):247-68, http://dx.doi. org/10.1080/10615800008549265.

12. Schaufeli WB, Greenglass ER. Introduction to special issue on burnout and health. Psychol Health. 2001;16(5):501-10, http://dx.doi.org/10.1080/08870440108405523.
13. Bakker AB. The crossover of burnout and its relation to partner health. Stress Health. 2009;25:4343-53, http://dx. doi.org/10.1002/smi.1278.

14. Pyzalski J. [Burnout, health and health behavior in teachers employed in correction institutions]. Med Pr. 2002;53(6): 495-9. Polish.

15. Burisch M. A longitudinal study of burnout: The relative importance of dispositions and experiences. Work Stress. 2002;16(1):1-17, http://dx.doi.org/10.1080/02678370110112506.

16. van der Linden D, Beckers DG, Taris TW. Reinforcement sensitivity theory at work: Punishment sensitivity as a dispositional source of job-related stress. Eur J Pers. 2007;21(7):889-909, http://dx.doi.org/10.1002/per.660.

17. Gable SL, Reis HT, Elliot AJ. Behavioral activation and inhibition in everyday life. J Pers Soc Psychol. 2000;78(6): 1135-49, http://dx.doi.org/10.1037/0022-3514.78.6.1135.

18. Langelaan S, Bakker AB, Doornen LJP, Schaufeli WB. Burnout and work engagement: Do individual differences make a difference? Pers Individ Dif. 2006;40(3):521-32, http://dx.doi.org/10.1016/j.paid.2005.07.009.

19. Thoresen C, Kaplan S, Barsky AP, Warren C, de Chermont $\mathrm{K}$. The affective underpinnings of job perceptions and attitudes: A meta-analytic review and integration. Psychol Bull. 2003;129(6):914-45, http://dx.doi.org/10.1037/00332909.129.6.914.

20. Palczynska E, Mojsa J. Does the psychoterapists's temperament influence the professional burnout syndrome? Research report. Ergonomia IJE\&HF. 2006;28(4):229-36.

21. Tucholska S. [Teacher burnout]. Lublin: Katolicki Uniwersytet Lubelski; 2003. Polish.

22. Maslach C, Leiter MP. Stress and burnout: The critical research. In: Cooper CL, editor. Handbook of stress medicine and health. London: CRC Press; 2005. p. 153-70.

23. Maslach C, Leiter MP. Early predictors of job burnout and engagement. J Appl Psychol. 2008;93(3):489-512, http:// dx.doi.org/10.1037/0021-9010.93.3.498.

24. Travers CJ, Cooper CL. Teachers under stress. Stress in the teaching profession. London: Routledge; 1996. 
25. De Heus P, Diekstra FW. Do teachers burn out more easily? A comparison of teachers with other social professions on work stress and burnout symptoms. In: Vandenberghe R, Huberman AM, editors. Understanding and preventing teacher burnout. Cambridge: Cambridge University Press; 1999. p. 269-84.

26. Kyriacou C. Teacher stress: Directions for future research. Educ Rev. 2001;53(1):27-35, http://dx.doi.org/10.1080/0013 1910120033628.

27. Johnson S, Cooper CL, Cartwright S, Donald I, Taylor P, Millet $\mathrm{C}$. The experience of work-related stress across occupations. J Manag Psychol. 2005;20(2):179-87, http://dx. doi.org/10.1108/02683940510579803.

28. Carlson BC, Thompson JA. Job burnout and job leaving in public school teachers: Implications for stress management. Int J Stress Manage. 1995;2(1):15-29, http://dx.doi.org/ 10.1007/BF01701948.

29. Dunham J. Stress in the workplace. Past, present, and future. Philadelphia (PA): Whurr Publishers, Ltd; 1992.

30. Chan DW. Stress, coping strategies and psychological distress among secondary school teachers in Hong Kong. Am Educ Res J. 1998;35(1):145-63, http://dx.doi.org/ 10.3102/00028312035001145.

31. Litt MD, Turk DC. Sources of stress and dissatisfaction in experienced high school teachers. J Educ Res. 1985;78:178-85.

32. Brotheridge CM, Grandey AA. Emotional labour and burnout: Comparing 2 perspectives of 'people work'. J Vocat Behav. 2002;60(1):17-39, http://dx.doi.org/10.1006/jvbe. 2001.1815.

33. Cano-Garcia FJ, Padilla-Munoz EM, Carrasco-Ortiz MA. Personality and contextual variables in teacher burnout. Pers Individ Dif. 2005;38(4):929-40, http://dx.doi.org/10. 1016/j.paid.2004.06.018.

34. Pyżalski J. [Source of teacher occupational stress]. In: Pyżalski J, Merecz D, editors. [Psychosocial working conditions of Polish teachers. Between burnout and engagement]. Kraków: Oficyna Wydawnicza Impuls; 2010. p. 53-74. Polish.

35. Rademaker AR, Kleber RJ, Geuze E, Vermetten E. Personality dimensions harm avoidance and self-directedness predict the cortisol awakening response in military men. Biol Psychol. 2009;81(3):177-83, http://dx.doi.org/10.1016/ j.biopsycho.2009.04.002.

36. Fontana DR, Abouserie R. Stress levels, gender and personality factors in teachers. Brit J Educ Psychol. 1993;63(2): 261-70, http://dx.doi.org/10.1111/j.2044-8279.1993.tb01056.x.

37. Mills L, Huebner E. A prospective study of personality characteristics, occupational stressors, and burnout among school psychology practitioners. J School Psychol. 1998;36(1): 103-20, http://dx.doi.org/10.1016/S0022-4405(97)00053-8.

38. Kokkinos CM. Job stressors, personality and burnout in primary school teachers. Br J Educ Psychol. 2007;77(1): 229-43, http://dx.doi.org/10.1348/000709905X90344.

39. Brackett MA, Palomera R, Mojsa-Kaja J, Reyes MR, Salovey P. Emotion regulation ability, burnout, and job satisfaction among British secondary school teachers. Psychol Sch. 2010;47(4):406-17, http://dx.doi.org/10.1002/pits.20478.

40. Watson D, Clark LA, Tellegen A. Development and validation of brief measures of positive and negative affect: The PANAS scales. J Pers Soc Psychol. 1988;54(6):1063-70, http://dx.doi.org/10.1037/0022-3514.54.6.1063.

41. Iverson RD, Olekalns M, Erwin PJ. Affectivity, organizational stressors, and absenteeism: A causal model of burnout and its consequences. J Vocat Behav. 1998;52(1):1-23, http://dx.doi.org/10.1006/jvbe.1996.1556.

42. Zellars KL, Hochwarter WA, Perrewé PL, Hoffman N, Ford EW. Experiencing job burnout: The roles of positive and negative traits and states. J Appl Soc Psychol. 2004;34(5): 887-911, http://dx.doi.org/10.1111/j.1559-1816.2004.tb02576.x.

43. Travers CJ, Cooper CL. Mental health, job satisfaction and occupational stress among UK teachers. Work Stress. 1993;7(3):203-19, http://dx.doi.org/10.1080/02678379 308257062.

44. Seidman SA, Zager J. A study of coping behaviours and teacher burnout. Work Stress. 1991;5(3):205-16, http:// dx.doi.org/10.1080/02678379108257019.

45. Bauer J, Stamm A, Virnich K, Wissing K, Müller U, Wirsching $\mathrm{M}$, et al. Correlation between burnout syndrome and 
psychological and psychosomatic symptoms among teachers. Int Arch Occup Environ Health. 2006;79(3):199-204, http://dx.doi.org/10.1007/s00420-005-0050-y.

46. Rudow B. Stress and burnout in the teaching profession: European studies, issues, and research perspectives. In: Huberman AM, editor. Understanding and preventing teacher burnout: A sourcebook of international research and practice. New York: Cambridge University Press; 1999. p. 38-58, http://dx.doi.org/10.1017/ CBO9780511527784.004.

47. Shirom A. Burnout in work organizations. In: Schaufeli WB, Maslach C, Marek T, editors. Professional burnout: Recent developments in theory and research. Washington (DC): Taylor \& Francis; 1993. p. 25-48.

48. Cloninger CR. Temperament and personality. Curr Opin Neurobiol. 1994;4(2):266-73, http://dx.doi.org/10.1016/09594388(94)90083-3.

49. Cloninger CR. The genetic structure of personality and learning: A phylogenetic model. Clin Benet. 1994; 46(1):124-37, http://dx.doi.org/10.1111/j.1399-0004.1994. tb04214.x.

50. Ravaja N, Keltikangas, Järvinen L, Kettunen J. Cloninger's temperament dimensions and threat, stress, and performance appraisals during different challenges among young adults. J Pers. 2006;74(1):287-310, http://dx.doi.org/10.1111/ j.1467-6494.2005.00376.x.

51. Mojsa J, Dylag A, Palczynska E. Psychometric properties of a Polish version of the Maslach Burnout Inventory - General Survey (MBI-GS) in a group of Information and Communication Technology (ICT) Specialists. Ergonomia IJE\&HF. 2006;28(4):351-61.

52. Hakanen J, Bakker AB, Schaufeli WB. Burnout and work engagement among teachers. J Sch Psychol. 2006;43(6): 495-513, http://dx.doi.org/10.1016/j.jsp.2005.11.001.

53. Chirkowska-Smolak T, Kleka P. The Maslach burnout inventory - General survey: Validation across different occupational groups in Poland. Pol Psychol Bull. 2011;42(2):86-94, http://dx.doi.org/10.2478/v10059-011-0014-x.
54. Leiter MP, Maslach C. The areas of worklife survey. Measure description. Wolfville: Acadia University, Center for Organizational Research and Development; 2004.

55. Mojsa-Kaja J. [Work adjustment, personality and emotion regulation ability and their effects on burnout] [unpublished dissertation]. Kraków: Jagiellonian University; 2008. Polish.

56. Cloninger CR, Przybeck TR, Svrakic DM, Wetzel RD. The Temperament and Character Inventory (TCI): A guide to its development and use. St Louis, Missouri: Center for Psychobiology of Personality; 1994.

57. Hornowska E. [Psychometric analysis of the Polish version of The Temperament and Character Inventory (TCI) R.C. Cloninger] [unpublished]. Poznań; 2003. Polish.

58. Hornowska E. Cloninger's Psychobiological model of personality and Strelau's regulative theory of temperament - Analysis of their association in a Polish sample. Pol Psychol Bull. 2011;42(2):71-80, http://dx.doi.org/10.2478/v10059-011-0011-0.

59. Brzozowski P. [Polish version of the PANAS (Positive and Negative Affect Schedule)]. Warszawa: Pracownia Testów Psychologicznych; 2010. Polish.

60. Billingsley BS, Cross LH. Predictors of commitment, job satisfaction, and intent to stay in teaching: A comparison of general and special educators. J Spec Educ. 1992;25(4): 453-71, http://dx.doi.org/10.1177/002246699202500404.

61. Martin NK, Sass DA, Schmitt TA. Teacher efficacy in student engagement, instructional management, student stressors, and burnout: A theoretical model using in-class variables to predict teachers' intent to leave. Teach Teach Educ. 2012; 28(4):546-59, http://dx.doi.org/10.1016/j.tate.2011.12.003.

62. Pelissolo A, Lepine JP. Normative data and factor structure of the Temperament and Character Inventory (TCI) in the French version. Psychiatry Res. 2000;94(1):67-76, http:// dx.doi.org/10.1016/S0165-1781(00)00127-X.

63. Leiter MP, Shaughnessy K. The areas of worklife model of burnout: Test of mediation relationships. Ergonomia IJE\&HF. 2006;28(4):327-41.

64. Karasek R, Theorell T. Stress, productivity, and the reconstruction of working life. New York: Basic Books, Inc.; 1990. 
65. Siegrist J. Adverse health effects of high-effort/low-reward conditions. J Occup Health Psychol. 1996;1(1):27-41, http:// dx.doi.org/10.1037/1076-8998.1.1.27.

66. BakkerAB,KillmerChH,SiegristJ,SchaufeliWB.Effort-reward imbalance and burnout among nurses. J Adv Nurs. 2000;31(4): 884-91, http://dx.doi.org/10.1046/j.1365-2648.2000.01361.x.

67. Halbesleben JRB, Buckley RM. Burnout in organizational life. J Manage. 2004;30(6):859-79, http://dx.doi.org/ 10.1016/j.jm.2004.06.004.

68. Swider BW, Zimmerman RD. Born to burnout: A meta-analytic path model of personality, job burnout, and work outcomes. J Vocat Behav. 2010;76(3):487-506, http://dx.doi.org/ 10.1016/j.jvb.2010.01.003.

69. Lundstrom M, Graneheim UH, Eisemann H, Richter J, Astrom S. Personality impact on experiences of strain among staff exposed to violence in care of people with intellectual disabilities. J Policy Pract Intellect Disabil. 2007;4(1):30-9, http://dx.doi.org/10.1111/j.1741-1130.2006.00095.x.

70. Pejuskovic B, Lecic-Tosevski D, Priebe S, Toskovic O. Burnout syndrome among physicians - The role of personality dimensions and coping strategies. Psychiatr Danub. 2011;23(4):389-95.

71. Demerouti E, Bakker AB, Nachreiner F, Schaufeli WB. The job demands-resources model of burnout. J Appl Psychol. 2001;86(3):499-512, http://dx.doi.org/10.1037/0021-9010.86.3.499.

72. Schaufeli WB, Bakker AB. Job demands, job resources, and their relationship with burnout and engagement: A multisample study. J Organ Behav. 2004;25(3):293-315, http:// dx.doi.org/10.1002/job.248.

73. Leiter MP, Gascon S, Martinez-Jarreta B. Making sense of work life: A structural model of burnout. J Appl Soc Psychol. 2010;40(1):57-75, http://dx.doi.org/10.1111/j.15591816.2009.00563.x.

74. Veugelers W, Vedder P. Values in teaching. Teach Teach Theor Pract. 2003;9(4):377-89, http://dx.doi.org/10.1080/ 1354060032000097262.
75. Sobolewki A, Strelau J, Zawadzki B. The temperamental determinants of stressors as life changes. Eur Psychol. 2001;6(4):28795, http://dx.doi.org/10.1027//1016-9040.6.4.287.

76. Cloninger CR. Feeling good: The science of well-being. New York: Oxford University Press; 2004.

77. Cloninger CR, Zohar AH. Personality and the perception of health and happiness. J Affect Disorders. 2011;128(1): 24-32, http://dx.doi.org/10.1016/j.jad.2010.06.012.

78. Seligman ME, Steen TA, Park N, Peterson C. Positive psychology progress: Empirical validation of interventions. Am Psychol. 2005;60(5):410-21, http://dx.doi.org/10.1037/ 0003-066X.60.5.410.

79. Avey JB, Luthans F, Youssef CM. The additive value of positive psychological capital in predicting work attitudes and behaviors. J Manage. 2010;36(2):430-52, http://dx.doi.org/ 10.1177/0149206308329961.

80. Verbruggen M, Sels L. Can career self-directedness be improved through counseling? J Vocat Behav. 2008;73(2): 318-27, http://dx.doi.org/10.1016/j.jvb.2008.07.001.

81. Garcia D, Kerekes N, Archer T. A will and a proper way leading to happiness: Self-directedness mediates the effect of persistence on positive affectivity. Pers Individ Dif. 2012;53(8):1034-8, http://dx.doi.org/10.1016/j.paid. 2012.07.025.

82. Cloninger CR. The science of well-being: An integrated approach to mental health and its disorders. World Psychiatry. 2006;5(2):71-6.

83. Quick JC, Quick JD, Nelson DL, Hurrell JJ. Preventive stress management in organizations. Washington (DC): American Psychological Association; 1997.

84. van der Klink JJ, Blonk RW, Schene AH, van Dijk FJ. The benefits of interventions for work-related stress. Am J Public Health. 2001;91(2):270-6, http://dx.doi.org/10. 2105/AJPH.91.2.270.

85. Hofstede G, Hofstede GJ. Cultures and organizations: Software of the mind. 2nd ed. New York: McGraw-Hill; 2005.

This work is available in Open Access model and licensed under a Creative Commons Attribution-NonCommercial 3.0 Poland License - http://creativecommons.org/ licenses/by-nc/3.0/pl/deed.en. 